\title{
OS BENEFÍCIOS DA TÉCNICA REIKI NA ANSIEDADE E ESTRESSE
}

\section{ARTIGO DE REVISÃO}

RUIZ, Sandra Silva Datore ${ }^{1}$

ARAÚJO, Maria Carolina Marques de Souza ${ }^{2}$

SILVA, Maristela Ribeiro da ${ }^{3}$

GARBIM, Rosana de Fátima ${ }^{4}$

RUIZ, Sandra Silva Datore. Et al. Os benefícios da técnica Reiki na ansiedade e estresse. Revista Científica Multidisciplinar Núcleo do Conhecimento. Ano 04, Ed. 09, Vol. 04, pp. 26- 36. Setembro de 2019. ISSN: 2448-0959, Link de acesso: https://www.nucleodoconhecimento.com.br/saude/beneficios-da-tecnica

\section{RESUMO}

O presente estudo tem como objetivo destacar os benefícios da Técnica Reiki na redução da ansiedade e do estresse trata- se de uma narrativa da literatura que busca analisar as pesquisas científicas mais relevantes, buscando a eficácia desta técnica. Foram realizadas a busca bibliográfica no período de janeiro a março de 2018. Considerando a base de dados, Scientific Electronic Library Onlin (SCIELO), Literatura Latino-Americana e do Caribe em Ciências da Saúde (LILACS), Medical Literature Analysis and Retrieval System Online (MEDLINE), com a seguinte combinações entre descritores: técnica reiki, ansiedade e estresse, benefícios do Reiki. Os resultados

1 Estudante do $11^{\circ}$ período de Medicina da Universidade Brasil- Campus Fernandópolis- SP.

2 Estudante do $11^{\circ}$ período de Medicina da Universidade Brasil- Campus Fernandópolis- SP.

${ }^{3}$ Fisioterapeuta. Mestre em Reiki.

${ }^{4}$ Fisioterapeuta. Mestre em Reiki. 
obtidos foram que a Técnica Reiki, atua de forma precisa nos casos de ansiedade ou de estresse, melhorando a vitalidade, proporcionando maior equilíbrio, calma e aumentando a imunidade, além de muitos outros benefícios como o controle da dor e bem estar físico global do indivíduo. Concluímos que esta técnica reiki é muito eficaz.

Palavras-Chave: Benefícios do Reiki, ansiedade, estresse.

\section{INTRODUÇÃO}

O Reiki constitui um sistema de cura através da imposição das mãos, utilizado para o tratamento do corpo físico, atuando nos corpos sutis etéreo, mental, emocional e espiritual, trazendo benefícios que vão além do corpo físico e agindo profundamente não somente nos sintomas, mas na causa destes. Trata-se de um tipo de terapia proveitosa oferecida a indivíduos em situação de saúde e de doença, uma vez que aumenta a energia vital e fortalece o sistema imunológico. (FREITAG et al 2014).

Segundo Freitag et al (2014), a palavra japonesa rei-ki compõe-se de duas sílabas: rei, que descreve o aspecto cósmico, universal, a energia, e ki, que significa a força vital fundamental que flui e pulsa em todos os seres vivos em formação individual. Representa um método de cura simples que permite absorver mais energia vital, potencializando e equilibrando a energia do ser humano.

De acordo com o Reiki é uma abordagem de saúde complementar no qual os praticantes colocam levemente as mãos sobre ou apenas acima de uma pessoa, com o objetivo de facilitar a resposta de cura, pois se fundamenta na ideia de que o Reiki mobiliza uma "energia vital universal" que dá suporte às habilidades inatas e naturais de cura do corpo e mente, fornecendo força, harmonia e equilíbrio. Originou- se há milhares de anos no Tibet e foi novamente estabelecida em 1800 por Dr. Mikao Usui, um monge japonês.

A imposição das mãos pelo Reikiano direciona a energia de cura para o corpo do receptor, que flui de forma vigorosa. O doador de Reiki serve como canal para transmitir a energia vital universal. Assim, nenhuma energia pessoal é absorvida ou 
drenada do doador, que é simultaneamente, após cada sessão de Reiki, recarregado e fortalecido. (KUREBAYASHI 2016).

De acordo com Motta (2014), em uma aplicação de Reiki não é necessário que o terapeuta direcione a energia para lugares específicos do corpo do paciente ou tenha a intenção de curá-lo, pois, pelo atributo "Rei" da energia o "Ki" se direciona para onde é necessário, o que atenua a preocupação do terapeuta em relação à perda de sua energia, pois esta ao passar pelo seu corpo antes de chegar ao paciente, beneficia também o terapeuta. Este é um dos motivos de não existirem contra indicações para o Reiki .

$\mathrm{Na}$ sociedade pós-moderna, os altos níveis de estresse se tornaram um problema de saúde muito comum e se percebe que o efeito excessivo e contínuo pode comprometer a saúde, tendo um efeito desencadeador no desenvolvimento de inúmeras doenças. Propiciam prejuízo para a qualidade de vida e a produtividade do ser humano, o que gera um grande interesse pelas causas e pelos métodos para sua redução. (KUREBAYASHI 2016).

Portanto o presente estudo tem como objetivo destacar os benefícios da Técnica Reiki na redução da ansiedade e do estresse, através de pesquisas científicas com a temática.

\section{METODOLOGIA}

A presente pesquisa trata- se de uma revisão narrativa de literatura que busca analisar as pesquisas científicas sobre os benefícios da técnica reiki na ansiedade e estresse.

Foram realizadas a busca bibliográfica no período de janeiro a setembro de 2018 . Considerando a base de dados, Scientific Electronic Library Onlin (SCIELO), Literatura Latino-Americana e do Caribe em Ciências da Saúde (LILACS), Medical Literature Analysis and Retrieval System Online (MEDLINE), com a seguinte combinações entre descritores: técnica reiki e ansiedade, estresse e ansiedade. 
Definiram-se como critérios de inclusão: publicações nacionais e internacionais relacionadas ao tema do estudo, publicados no período entre 2005 a 2018 e disponibilizadas online em forma de artigo completo ou apenas em forma de resumos, livros e periódicos.

Excluíram-se publicações que não contemplavam a temática em questão ou que não estavam disponíveis online.

Optou-se por esse período de referência, pois foi quando os estudos acerca dessa temática ganharam maior ênfase, tanto no cenário nacional quanto internacional, nesta última década.

\section{MÉTODO REIKI}

Segundo Motta (2014), dentre as práticas integrativas e complementares encontradas no Brasil, em pesquisa realizada pelo Ministério da Saúde em 2004, o reiki foi identificado como prática utilizada no Sistema Único de Saúde (SUS) (25,6\%).Isso pode ser atribuído a grande número de motivos, dentre eles, o fato de não necessitar de procedimentos invasivos, com raros registros de contraindicação, não necessitar de esforço físico e possibilitar a prática de restabelecimento de energia de fácil e simples acesso. Nos Estados Unidos, o National Center of Complementary and Alternative Medicine (NCCAM) caracteriza o reiki como terapia complementar.

$\mathrm{Na}$ aplicação da técnica Reiki o terapeuta entra em um estado de relaxamento profundo, no qual ele consegue maior serenidade e tranquilidade por isso, transtornos como depressões cedem, e essas pessoas começam a ver em perspectiva sua vida e seus problemas, muitas vezes obtendo soluções, além de um autoconhecimento muito maior. Tudo isso proporciona mais felicidade, trazendo equilíbrio ao corpo. ( SANTOS et al, 2018)

Ainda Santos et al (2018) refere que o Reiki merece ser entendido neste contexto de metodologias holísticas de saúde e sua aplicação deve corresponder a esse entendimento. Especialmente desde que o Reiki se tornou conhecido pelos humanos 
graças à prática dos ensinamentos holísticos, pelo seu desenvolvedor Mikao Usui. Em relação a essa origem, o Reiki pode ser reconhecido como um tesouro de ensinamentos revelados para esses tempos, dentro do vasto Dharma universal.

De acordo com Costeira (2009), o Reiki tem como finalidade equilibrar o campo vibracional corpo/mente, apesar de ainda não existir uma teoria explicativa ou o mecanismo pelo qual o Reiki funciona. Alguns investigadores têm vindo a explorar a função potencial dos campos bioelectromagnéticos nos processos fisiológicos e estão a tentar estabelecer uma conexão teórica capaz de permitir compreender os mecanismos subjacentes ao Reiki e outras terapias pelo toque.

O Reiki parte do princípio de que a força vital flui pelo corpo físico, através de canais e centros de energia chamados meridianos e Chakras - força que sustenta os órgãos e células do corpo - apoiando - se nas suas funções vitais. Quando a força vital se encontra perturbada, afeta o campo energético do corpo e pode ter um impacto negativo sobre os órgãos ou tecidos. Durante o tratamento de Reiki o terapeuta atua como veículo condutor da energia que é transmitida às partes afetadas do campo energético do paciente, carregando-as de energia positiva e retirando a energia negativa que origina doenças e stresse. (COSTEIRA 2009).

\section{TÉCNICA REIKI NA ANSIEDADE E ESTRESSE}

A ansiedade e o estresse têm suas raízes em diversas reações motivadas pela emoção de medo, do ponto de vista biológico em resposta aos perigos encontrados no meio ambiente, quando, por exemplo, um animal depara com uma ameaça ao seu bem-estar, à sua integridade física, ou até mesmo à sua sobrevivência. Em seu aspecto social, devido a inúmeros aspectos da vida moderna que geram reações de preocupação, tensão e medo. Esses sintomas, de estresse e ansiedade, produzem, portanto, um estado de vigilância no organismo, a fim de que o indivíduo possa se manter alerta para enfrentar desafios naturais e/ou sociais. (MOTTA, BARROS, 2015)

O Reiki atua de forma precisa nos casos de ansiedade ou de estresse, quando os níveis altos de descontrole emocional geram desarmonia das funções primordiais do 
corpo, resultando num desequilíbrio interno da pessoa, diminuindo suas defesas. É importante ressaltar que o desequilíbrio físico em decorrência do desequilíbrio emocional, é um forte indício de que seu corpo precisa de ajuda imediata para voltar a funcionar em perfeita harmonia.

As queixas de nervosismo, estresse e ansiedade são comuns na população idosa, principalmente quando sentem dor contínua. Nesse contexto, atenta-se para a introdução de práticas complementares, com a finalidade de melhorar a qualidade de vida desta parcela da população, visto que obtiveram melhora significativa da dor e, consequentemente, referiram melhora da ansiedade, do nervosismo e do estresse, após o tratamento com Reiki. (FREITAG et al; 2014).

O estresse é uma resposta complexa do organismo, que envolve reações físicas, psicológicas, mentais e hormonais diante de qualquer evento que seja interpretado pela pessoa como desafiante. Esse estímulo, interpretado como desafiador, provoca uma quebra na homeostase do funcionamento interno, que, por sua vez, cria uma necessidade de adaptação para preservar o bem-estar e a vida. (MOTTA, BARROS, 2015).

Sendo diretamente envolvido na resposta ao estresse, o cortisol (ou hidrocortisona) é o principal glicocorticoide produzido pelo córtex suprarrenal, que afeta profundamente o metabolismo da glicose, das proteínas e dos ácidos graxos livres. Após sua síntese, o cortisol passa para a corrente sanguínea, onde a maior parte (mais de $60 \%$ ) se encontra ligada a proteínas (SHBG e albumina), e o restante encontra-se livre no plasma, que é a forma ativa. Os efeitos biológicos do cortisol incluem: o catabolismo de proteínas em todas as células do organismo, facilita a ação de outros hormônios, funciona como antagonista da insulina, promove a ativação de lipase e a degradação dos triglicerídeos no tecido adiposo, promove a adaptação ao estresse e a manutenção de níveis de glicose adequados mesmo em períodos de jejum (MCARDLE; KATCH; KATCH, 2008).

O cortisol também é conhecido por diminuir a utilização de glicose, poupando-a para o cérebro, por atuar como um agente anti-inflamatório. (WILMORE; COSTILL, 2001). 
Segundo Kurebayashi et, al (2016), os sintomas gerais de estresse reduzidos com os tratamentos demonstram que o estresse afeta todos os sistemas do corpo resultando em alterações fisiológicas e psicológicas. No estresse, o córtex cerebral envia sinais para o sistema nervoso autônomo e o simpático torna-se ativo, resultando em aumento da frequência cardíaca e mudanças na variabilidade da frequência, diminuindo o fluxo sanguíneo periférico e o fluxo sanguíneo renal, levando ao aumento da pressão arterial e da resistência vascular.

Ainda o autor do estudo, afirma que a massagem associada ao reiki conseguiu ampliar os $24,0 \%$ de redução dos níveis de estresse e $16,0 \%$ dos indivíduos do grupo Massagem e Repouso (G1), para 33,0\% de estresse e $21,0 \%$.

Considere-se que foram apenas 10 minutos de Reiki pós-massagem e os resultados positivos da combinação de Massagem+Reiki mostraram que a associação de duas técnicas energéticas conseguiu reduzir o tempo de atendimento usual para o Reiki. Os outros estudos utilizaram cerca de 20 a 30 minutos nas sessões de Reiki, como técnica única. (KUREBAYASHI et al, 2016).

Outro estudo avaliou o efeito de 30 minutos de Reiki no controle de ansiedade, dor e bem-estar global em pacientes com câncer (118 pacientes), em tratamento quimioterápico. Avaliações antes e depois da aplicação do Reiki promoveram melhoria no bem-estar, qualidade do sono, relaxamento, alívio da dor, e redução dos níveis de ansiedade.

De acordo com Honervogt (2005), o reiki equilibra harmoniosamente todos os aspectos do ser do receptor, de acordo com suas necessidades e desejos pessoais. Equilibra os órgãos e glândulas e suas funções corporais; libera bloqueios e emoções reprimidas; promove equilíbrio; adapta-se as necessidades naturais do receptor; equilibra as energias do corpo; amplia a consciência pessoal e facilita os estados meditativos; relaxa e reduz o stress; estimula a criatividade; potencializa a energia vital, aguça a intuição; trata os sintomas e as causas das doenças; cura holisticamente; fortalece o sistema imunológico; alivia a dor; libera toxinas. 
De acordo com Rodriguez el al (2011), o autocuidado proativo, através de Reiki, é estratégia capaz de prevenir a Síndrome de Burnout em enfermeiras. O Reiki é uma modalidade curativa corpo/mente que visa ajudar no restabelecimento do sistema energético corporal, graças ao estímulo dos processos equilíbrio do organismo. Esse, muitas vezes, é utilizado para induzir o relaxamento e tratar de problemas de saúde como a dor musculoesquelética, a ansiedade e a depressão.

Os praticantes de Reiki utilizam a abordagem através de ligeiro contato manual para facilitar a abertura dos seus próprios canais energéticos e, também, dos pacientes. As enfermeiras que usam o Reiki para seu autocuidado descreveram a capacidade desse recurso terapêutico para ajudar no manejo do estresse e, também, na redução dos sintomas associados à Síndrome de Burnout (SB). (RODRIGUEZ et al, 2011)

Ainda o autor afirma em seu estudo realizados com enfermeiras com a Síndrome de Burnout, que uma única sessão de Reiki produz melhora imediata da função imunológica ( $\lg A s)$ e da regulação da pressão arterial.

De acordo com Sousa et al, (2012), pesquisas apontam que em pessoas com stress, ansiedade e depressão verificou-se: redução dos sintomas depressivos a longo prazo, em pessoas com sintomas de depressão e stress, após sessões que variavam entre 1h a 1 h30 minutos, uma vez por semana, durante seis semanas e melhoria do humor global em estudantes com um índice de ansiedade/ou depressão elevado, quando aplicado 30 minutos de Reiki durante 2 a 8 semanas.

Ainda Sousa et al (2012) refere que um estudo em pessoas submetidas a Reiki, verificou-se a diminuição da ansiedade e uma melhor capacidade de lidar com situações estressantes e em idosos que participaram em sessões de 45 minutos, uma vez por semana, durante oito semanas, referiram sentir: relaxamento, melhoria dos sintomas físicos, do humor e do bem-estar, tiveram curiosidade e desejo de aprender mais sobre o Reiki, bem como, referiram ainda melhoria do autocuidado e das respostas sensoriais e cognitivas. 


\section{CONSIDERAÇÕES FINAIS}

Esta pesquisa objetivou destacar os benefícios da técnica Reiki na ansiedade e estresse, e concluiu que o método reiki, atua de forma precisa nos casos de ansiedade ou de estresse, melhorando a vitalidade, proporcionando maior equilíbrio, calma e aumentando a imunidade, além de muitos outros benefícios à saúde e qualidade de vida.

Pois quando os níveis altos de descontrole emocional geram desarmonia das funções primordiais do corpo, resultando num desequilíbrio interno da pessoa, diminuindo suas defesas. É importante ressaltar que o desequilíbrio físico em decorrência do desequilíbrio emocional, é um forte indício de que seu corpo precisa de ajuda imediata para voltar a funcionar em perfeita harmonia.

O Reiki merece ser entendido neste contexto de metodologias holísticas de saúde, e sua aplicação deve corresponder a esse entendimento.

Especialmente desde que o Reiki se tornou conhecido pelos humanos graças à prática dos ensinamentos holísticos, pelo seu desenvolvedor Mikao Usui.

É de suma importância destacar que a técnica Reiki deve ser realizada quando o terapeuta tem o total conhecimento de como aplica-la e de seus benefícios.

\section{REFERÊNCIAS}

COSTEIRA, B. R. C. Influência da Terapia de Reiki em Indicadores de Saúde. International Journal of Developmental and Educational Psychology, vol. 1, núm. 1, 2009, pp. 465-471 Asociación Nacional de Psicología Evolutiva y Educativa de la Infancia, Adolescencia y Mayores Badajoz, España. Disponível em: $<$ https://www.redalyc.org/pdf/3498/349832320050.pdf>. Acessado em: 15 de abrl de 2018.

DÍAZ-RODRÍGUEZ L., ARROYO-MORALES M., CANTARERO-VILLANUEVA I., FÉRNANDEZ-LAO C., POLLEY M., FERNÁNDEZ-DE-LAS-PEÑAS C. Uma sessão 
de Reiki em enfermeiras diagnosticadas com síndrome de Burnout tem efeitos benéficos sobre a concentração de IgA salivar e a pressão arterial. Rev. LatinoAm. Enfermagem [Internet]. set.-out. 2011. Disponível em: <http://www.scielo.br/pdf/rlae/v19n5/pt_10>. Acessado em: 10 de abr de 2018.

FREITAG, VERA LUCIA, SARTORI DALMOLIN, INDIARA, ROSSATO BADKE, MARCIO, DE ANDRADE, ANDRESSA, Benefícios do reiki em população idosa com dor crônica. Texto \& Contexto Enfermagem [en linea] 2014, 23 (OctubreDiciembre): [Fecha de consulta: 26 de junio de 2019]. Disponível em : <http://www.redalyc.org/articulo.oa?id=71433508026> ISSN 0104-0707 Acessado: em 02 fev.2018.

HONERVOGT T. Reiki Cura e Harmonia Através das Mãos. 4th ed. São Paulo: Pensamento; 2005.

KUREBAYASHI LFS, TURRINI RNT, SOUZA TPB, TAKIGUCHI RS, KUBA G, NAGUMO MT. Massage and Reiki used to reduce stress and anxiety: Randomized Clinical Trial. Rev. Latino-Am. Enfermagem. 2016;24:e2834. Disponível em: DOI: <http://dx.doi.org/10.1590/1518-8345.1614.2834>. Acessado em : 10 de mai de 2018.

MOTTA, PEDRO MOURÃO ROXO DA, 1985- M858a. Aplicação das técnicas de imposição de mãos no câncer, dor e stress ansiedade : revisão sistemática da literatura / Pedro Mourão Roxo da Motta. - Campinas, SP : [s.n.], 2014. Disponível em: Disponível em: <http://doi.editoracubo.com.br/10.4322/0104-4931.ctoAR0534> Acesso em: 07 abril de 2018.

MOTTA, R. M. P. BARROS. F. N. A aplicação de técnicas de imposição de mãos no estresse-ansiedade: revisão sistemática da literatura. Laboratório de Práticas Alternativas Complementares e Integrativas em Saúde - Lapacis, Departamento de Saúde Coletiva, Faculdade de Ciências Médicas, Universidade Estadual de Campinas - Unicamp, Campinas, SP, Brasil. Cad. Ter. Ocup. UFSCar, São Carlos, v. 23, n. 2, p. 
381-392, 2015. Disponível em: <http://doi.editoracubo.com.br/10.4322/01044931.ctoAR0534> Acesso em: 07 abril de 2018.

MCARDLE, W.D.; KATCH, F.I.; KATCH, V.L. Fisiologia do exercício: Energia, nutrição e desempenho humano. 6ª ed. Rio de Janeiro: Guanabara Koogan, 2008.

SANTOS, Antonio Marcos Batista dos; SILVA, Regivania Sousa; IBRAHIM, Divina Gonsalves Borges. O Reiki como Terapia Complementar na Prática de Enfermagem. Revista Científica Multidisciplinar Núcleo do Conhecimento. Ano 03, Ed. 08, Vol. 04, pp. 164-185, Agosto de 2018. ISSN:2448-0959. Disponível em: $<$ https://www.nucleodoconhecimento.com.br/saude/reiki-como-terapia $>$.Acessado em 02 set de 2018.

SOUSA, M. M. L; SEVERINO. P. S. S; VIEIRA. M. A. M C. Artigo: O Reiki como um Contributo para a Prática de Enfermagem: Revisão Sistemática da Literatura. 2012. Disponível em: file:///C:/Users/55179/Downloads/42_2012-com-revisao-revistoluis-sousa.pdf. Acessado em: 20 de mar de 2018.

WILMORE J.H; COSTILL D.L. Fisiologia do esporte e do exercício. São Paulo. Manole. P.709, 2001.

Enviado: Maio, 2019.

Aprovado: Setembro, 2019. 